DOI: $10.17516 / 1997-1397-2021-14-2-176-183$

УДК $537.9+539.216 .2$

\title{
Manufacturing of Opals from Polymethylmethacrylate Particles in Dispersion Media with Different Viscosities
}

\author{
Ivan V. Nemtsev* \\ Federal Research Center KSC SB RAS \\ Krasnoyarsk, Russian Federation \\ Kirensky Institute of Physics, Federal Research Center KSC SB RAS \\ Krasnoyarsk, Russian Federation \\ Siberian Federal University \\ Krasnoyarsk, Russian Federation \\ Olga V.Shabanova ${ }^{\dagger}$
}

Special Designing and Technological Bureau "Nauka" Krasnoyarsk, Russian Federation

Received 06.10.2020, received in revised form 23.10.2020, accepted 10.01.2021

\begin{abstract}
The article was prepared based on the materials of the report at the first All-Russian scientific conference with international participation "YENISEI PHOTONICS - 2020".

Photonic crystals are structures that have a spatial architecture with a periodically changing complex dielectric function at scales comparable to the wavelengths of light in the visible frequency range. The purpose of this study is to obtain three-dimensional photonic crystals by self-assembly from submicron spherical monodisperse particles of polymethylmethacrylate in dispersion media with different viscosities.

Keywords: emulsion-free polymerization, viscosity of dispersion medium, PMMA beads, submicrosphere, self-assembly, 2D and 3D colloidal crystals, photonic crystal, metamaterial, SEM micrographs, IR spectroscopy.
\end{abstract}

Citation: I.V. Nemtsev, O.V. Shabanova, Manufacturing of Opals from Polymethylmethacrylate Particles in Dispersion Media with Different Viscosities, J. Sib. Fed. Univ. Math. Phys., 2021, 14(2), 176-183. DOI: 10.17516/1997-1397-2021-14-2-176-183.

\section{Introduction}

Photonic crystals (PhCs) are considered promising optical materials for basic research and practical application in various fields of technology due to their outstanding properties, such as photonic bandgap (PBG), light wavelength selectivity, and high-performance photoluminescence [1-3]. Among PhCs, opals (artificial and natural) stand out as a special class. Opals are threedimensional periodic structures of vivid interest [4-6]. This is due to the fact that such materials can be produced using relatively simple and inexpensive production methods, as well as the presence of a significant surface area of three-dimensional, high-precision, ordered opal patterns. It is obvious that the most suitable method for obtaining a colloidal crystal is the self-assembly approach [4], the most popular techniques of which are gravitational deposition, vertical deposition, meniscus deposition, etc. [7-9]. Artificial opals can be manufactured using polymer microand nanosized beads [10-12]. Based on these spheres it is possible to form perfectly ordered 2D [13] and 3D [14] mesoporous structures - PhCs or metamaterials. In its turn, polymethylmethacrylate (PMMA) is seemed to be the reassuring and advantageous polymer in the field

\footnotetext{
*ivan_nemtsev@mail.ru https://orcid.org/0000-0002-4222-3099

$\dagger$ 'ollach@yandex.ru

(c) Siberian Federal University. All rights reserved
} 
of using in biomedical practical implementation [15-17], applications in nanotechnology [18-21], sensor [22-24], optical [25, 26], solar cell technology [27-32]. A classical approach to synthesize PMMA spheres is emulsion-free polymerization. The physicochemical properties of such particles are well studied. Notwithstanding, using a more complex dispersion medium, it is possible to modify [33] the polymerization technique and obtain microparticles with variable properties [34]. In this work, the three-dimensional PhCs based on the submicron spherical monodisperse particles of PMMA obtained in dispersion media with different viscosities are fabricated by selfassembly approach. As a dispersion medium, distilled water with addition of dimethyl sulfoxide and acetone was used. The bead's sizes were in the range of 315-400 $\mathrm{nm}$. The morphological, some physicochemical, and optical reflectance features of obtained samples were studied.

\section{Experimental procedures}

\subsection{Synthesis of PMMA spheres}

To synthesize PMMA emulsion methyl methacrylate (MMA), distilled water, dimethyl sulfoxide, distilled acetone, and an initiator. 2,2-azobis dihydrochloride (2-methylpropionamidine) were used without further purification. A necessary condition of a dispersion polymerization of polymer-based the submicrobeads with a narrow size distribution is a short phase of intensive multiple germ formation, followed by slow controlled growth of particles without changing their number. The process of chain radical polymerization of methyl methacrylate can be divided into three stages: activation of the initiator, the reaction of the monomer with the initiator radical, and growth of the molecule and breaking of the polymer chain. When heated, the initiator decomposes to form active radicals, which are the initiators of the polymerization reaction.

The emulsion polymerization procedure requires heating of methyl methacrylate emulsified in water to $70 \div 80^{\circ} \mathrm{C}$. In this study, the emulsion temperature was maintained from 72.7 to $75^{\circ} \mathrm{C}$. As a control sample, PMMA submicroparticles in an aqueous medium (100 ml of methyl methacrylate (MMA) and $620 \mathrm{ml}$ of distilled water) were obtained by a classical emulsifier-free polymerization technique [35]. The speed of the mixer was fixed at $700 \mathrm{rpm}$. To synthesize the particles with variable properties, dispersion media were selected with the addition of dimethyl sulfoxide (DMSO) (100 ml MMA, $550 \mathrm{ml}$ distilled water, $70 \mathrm{ml}$ DMSO) and acetone (100 ml MMA, $550 \mathrm{ml}$ distilled water, $70 \mathrm{ml}$ acetone). Thus, the volume of MMA and the total volume of the emulsion were constant: 100 and $720 \mathrm{ml}$, respectively. The volume concentrations of acetone and DMSO were taken at random.

During the synthesis of submicroparticle dispersion, the IR spectra of the dispersion were recorded in situ by using the FT-801 IR Fourier spectrometer with a fiber probe [36]. Thus, the polymerization process is fully controlled with the IR spectra. Consequently, all the chemical reagents are assumed fully reacted.

\subsection{Manufacturing of PMMA opal-like photonic crystal structures}

In this work, the PMMA colloidal crystals were self-assembled $[9,37]$ on cover glasses by methods of natural sedimentation in a gravitational field, vertical deposition by evaporation, and meniscus. Humidity in a laboratory box was constantly kept at $70 \%$ and the temperature was constantly maintained at $24^{\circ} \mathrm{C}$. Square pieces of $4 \times 4 \mathrm{~mm}$ were cut from the cover glass and deposited with a thin film of $3 \mathrm{~nm}$ platinum in a sputter coater to provide electrical conductivity in the SEM chamber. To minimize the damage of the PMMA opal films, the coating modes were

as follows: three cycles of $20 \mathrm{~s}$ with a set current of $10 \mathrm{~mA}$. It also used argon gas to purge the chamber of the spray coating device. 


\subsection{Instrumentation}

In situ measurements of disturbed total internal reflection were performed with an FT-801 IR Fourier spectrometer (Simex, Novosibirsk, Russia) to control the synthesis process. To ensure electrical conductivity a K575XD (Emitech, UK) magnetron sputtering coating system was used to cover the PMMA opal surface with a thin platinum film. Morphological features of the samples were obtained with a high-resolution field emission scanning electron microscope (FE-SEM) S-5500 (Hitachi, Japan) at an accelerating voltage of $3 \mathrm{kV}$ a probe current of $10 \mathrm{nA}$. Steady-state attenuated total reflectance spectroscopy was performed with the FTIR-spectrometer Vertex 70 (Bruker, Germany).

\section{Results and discussion}

The bead's sizes by measuring diameters, their sphericity, shrinkage degree as well as polydispersity were estimated during SEM studies of the morphological features of the obtained particles.
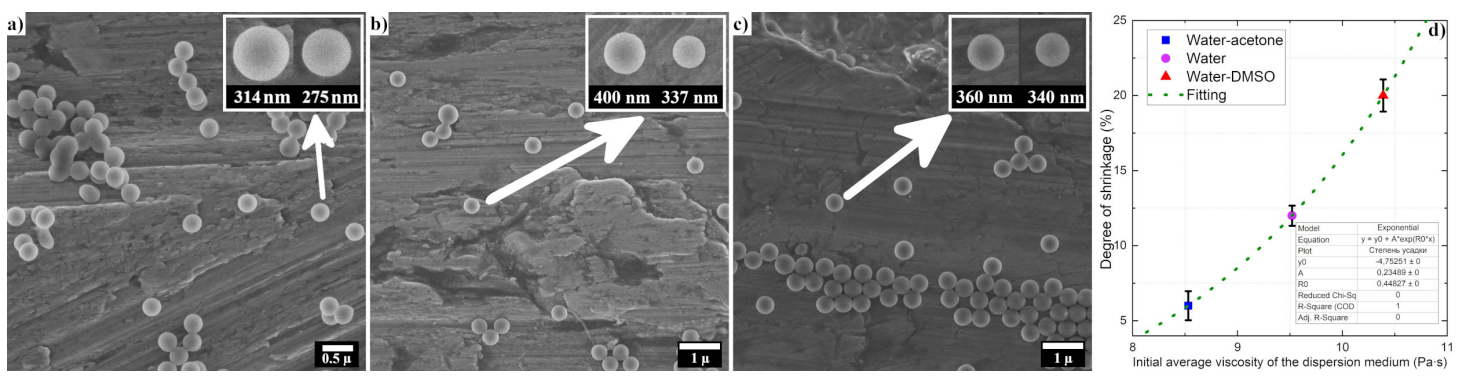

Fig. 1. SEM images of submicroparticles from PMMA obtained in (a) an aqueous medium; (b) an aqueous-DMSO dispersion medium; (c) an aqueous-acetone dispersion medium; (d) a dependence of shrinkage of PMMA submicroparticles on initial average viscosity of the dispersion medium

It was found that the additives significantly affect the size and degree of the shrinkage of the synthesized particles [38]. The bead's sizes of the control sample, "DMSO" sample, and "acetone" sample were 315, 400, and $360 \mathrm{~nm}$, respectively. So, SEM revealed (Fig. 1) a different degree of the shrinkage of the PMMA submicrospheres under the influence [39] of the electron beam $(3 \mathrm{kV}, 10 \mathrm{nA})$ depending on the dispersion medium in which they were obtained. As shown, the "DMSO" sample has the maximum shrinkage of all the studied samples. It is $16 \%$. The smallest shrinkage is shown has the "acetone" sample. It is only $6 \%$. Moreover, beads obtained under different conditions were deformed in different degrees during sample preparation. Fig. 1a and $1 \mathrm{~b}$ show that some of the submicroparticles are no longer spherical. The «acetone» spheres were the largest and the most spherical. The concentration of particles, for example, in the aqueous dispersion was estimated as 15 vol.\% ( $6^{15}$ nanoparticles per liter). According to SEM, the polydispersity of nanoparticles was less than $5 \%$.

The various properties of spherical particles are primarily due to the viscosity of the dispersion medium. The classical Grunberg-Nissan [40] rule for a liquid mixture was used to estimate the average initial viscosity:

$$
\ln \mu_{\text {mix }}=\sum x_{i} \ln \mu_{\mathrm{i}}
$$

where $\mu_{\text {mix }}$ is the viscosity of the liquid mixture; $\mu_{\mathrm{i}}$ is the viscosity of the liquid component $i ; x_{i}$ is the molar fraction of component $i$ in the liquid mixture. 
In the case of emulsifier-free emulsion polymerization, the reaction also begins in the medium phase with the formation of surface-active oligomeric forms resulting from the decomposition of the initiator. The diffusion of the formed primary particles can be described using the StokesEinstein relation:

$$
D=\left(k_{b} T\right) / 6 \pi \eta r,
$$

where $\mathrm{T}$ is the absolute temperature, $k_{b}$ is the Boltzmann constant, $\eta$ is the viscosity of the liquid, $r$ is the radius of the particle.

The surface tension and the solubility index of the dispersion medium also play a significant role. The addition of DMSO and acetone to the dispersion medium increases the solubility of the monomer. Similarly, the additives benefit to increase the solubility of the resulting polymer. As a result, longer polymer chains are formed. From longer polymer chains, nanoglobules are formed that capture a larger amount of the dispersion medium (with an increased concentration of monomer). Thus, by the time of the gel effect, the particles in the acetone and DMSO dispersion medium contain more MMA and growing oligomers in comparison with «water» particles. Thus, by selecting a balance between the above parameters, it is possible to obtain PMMA submicrospheres with variable properties.

In this work, three-dimensional opal templates are obtained (Fig. 2) based on the submicron monodisperse [41] spherical PMMA particles in various dispersion media [42] and investigated by SEM and IR spectroscopy.


Fig. 2. SEM images of the (111) opal's surfaces based on PMMA submicrospheres obtained in a) an aqueous medium (the inset shows the Fourier transform, demonstrating monocrystalline structure); b) an aqueous medium with the addition of $70 \mathrm{ml}$ of DMSO; c) an aqueous-acetone medium (70 $\mathrm{ml}$ of acetone). d) Absolute reflection spectrum obtained from the (111) surface shown in Fig. 2a

Figs. 2a-2c demonstrate the surfaces (111) of the PMMA photonic crystals manufactured by self-assembly in aqueous, aqueous-DMSO, and aqueous-acetone dispersion media, respectively. A non-defected long-range order of perfectly-ordered submicrospheres was discovered only in the aqueous sample. Fourier transform, demonstrating a single crystal structure, was performed using ImageJ open-source software. SEM micrograph of the surfaces (111) of the aqueous-DMSO sample in Fig. 2b shows multiple defects: domains, twinning, extra planes, vacancies, spheres of larger and smaller sizes. But nevertheless, these defects are very quickly "healed", the structure is restored. The inset demonstrates a quasi-crystalline structure. Finally, the aqueous-acetone sample showed the most disordered structure. The Fourier transform illustrates a polycrystalline structure.

To verify the long-range order in the most ordered opal a reflectance spectrum from the (111) surface was obtained with IR spectrometer Vertex $70 \mathrm{~V}$ (Fig. 2d). The absolute reflection of the sample was $86 \%$ at an angle of incidence of $12^{\circ}$ relative to normal. According to Bragg's Law, the maximum reflectivity is observed in a normal fall [41]. Thus, it can be argued that the reflectivity of the best opal photonic crystal structure obtained in an aqueous dispersion medium 
is significantly higher than $86 \%$. Moreover, from the reflectance spectrum, full width at half maximum and a quality factor at the PBG center of $\lambda=865 \mathrm{~nm}$ were determined as $70 \mathrm{~nm}$ and 12.4 , respectively.

\section{Conclusion}

In this study, the submicron spherical monodisperse PMMA particles are synthesized in the dispersion media with different viscosities. On their basis, the method of self-assembly is used to manufacture the various $\mathrm{PhC}$ opal templates with different hierarchy (from polycrystalline to monocrystalline with high degree of ordering).

Morphological features of the obtained beads and opals were carefully investigated by FESEM. The particle sizes, their sphericity, polydispersity, shrinkage degree as well as crystalline order were estimated. It was experimentally found that the impurities significantly affect the size and degree of the shrinkage of the synthesized spheres. Thus, SEM revealed the decreasing of the diameters from 400 to $314 \mathrm{~nm}$ and the increasing of the shrinkage degree with the increasing of the initial average viscosity of the dispersion medium.

The reflectance spectrum from the (111) surface was obtained by IR spectroscopy. The nondefected long-range order of perfectly-ordered submicrospheres was discovered. The absolute reflection of the bests sample was $86 \%$ at an angle of incidence of $12^{\circ}$ relative to normal. The quality factor of that sample was calculated as 12.4 .

The study was carried out with the support of the Krasnoyarsk Regional Center of Research Equipment of Federal Research Center "Krasnoyarsk Science Center SB RAS". The work was supported by the framework of the state assignment of the Ministry of Science and Higher Education of the Russian Federation (topic no. AAAA-A18-118041990041-8).

\section{References}

[1] J.Zhou, et al., Large-area crack-free single-crystal photonic crystals via combined effects of polymerization-assisted assembly and flexible substrate, NPG Asia Mater, 4(2012), e21.

DOI: $10.1038 / \mathrm{am} .2012 .38$

[2] P.Lova, G.Manfredi, D.Comoretto, Advances in Functional Solution Processed Planar 1D Photonic Crystals, Adv. Opt. Mater, 6(2018), 1800730-1800756.

DOI: 10.1002 /adom.201800730

[3] M.Bellingeri, A.Chiasera, I.Kriegel, F.Scotognella, Optical properties of periodic, quasiperiodic, and disordered one-dimensional photonic structures, Opt. Mater. (Amst), 72(2017), 403-421. DOI: 10.1016/j.optmat.2017.06.033

[4] J.Zhang, Z.Sun, B.Yang, Self-assembly of photonic crystals from polymer colloids, Curr. Opin. Colloid. Interface Sci., 14(2009), 103-114.

[5] G.I.N.Waterhouse, M.R.Waterland, Opal and inverse opal photonic crystals: Fabrication and characterization, Polyhedron, 26(2007), 356-368.

[6] E.Armstrong, C.O'Dwyer, Artificial opal photonic crystals and inverse opal structures fundamentals and applications from optics to energy storage, J. Mater. Chem. C, 3(2015), 6109-6143.

[7] Q.Zhao, et al., Large-scale ordering of nanoparticles using viscoelastic shear processing, Nat. Commun, $\mathbf{7}(2016), 11661$. DOI: 10.1038/ncomms11661 
[8] Q.Zhao, et al., Nanoassembly of Polydisperse Photonic Crystals Based on Binary and Ternary Polymer Opal, Alloys, Adv. Opt. Mater, 4(2016), 1494-1500.

DOI: $10.1002 /$ adom.201600328

[9] G.Shang, et al., Transparency induced in opals via nanometer thick conformal coating, Sci. Rep. 9(2019), 1-7. DOI: 10.1038/s41598-019-47963-2

[10] Z.Z.Gu, et al., Self-assembly of monodisperse spheres on substrates with different wettability, Appl. Phys. A Mater. Sci. Process., 81(2005), 47-49.

[11] J.-H.Lee, et al., 25th Anniversary Article: Ordered Polymer Structures for the Engineering of Photons and Phonons, Adv. Mater., 26(2014), 532-569. DOI: 10.1002/adma.201303456

[12] G.I.N.Waterhouse, W.T.Chen, A.Chan, D.Sun-Waterhouse, Achieving Color and Function with Structure: Optical and Catalytic Support Properties of $\mathrm{ZrO} 2$ Inverse Opal Thin Films, ACS Omega, 3(2018), 9658-9674. DOI: 10.1021/acsomega.8b01334

[13] J.F.Galisteo, et al., Self-assembly approach to optical metamaterials, J. Opt. A Pure Appl. Opt, 7(2005), S244-S254.

[14] A.Baron, A.Aradian, V.Ponsinet, P.Barois, Self-assembled optical metamaterials, Opt. Laser Technol, 82(2016), 94-100. DOI: 10.1016/j.optlastec.2016.02.024

[15] Y.Chen, L.Zhang, G.Chen, Fabrication, modification, and application of poly(methyl methacrylate) microfluidic chips, Electrophoresis, 15(2008).

[16] C.Bouzigues, T.Gacoin, A.Alexandrou, Biological Applications of Rare-Earth Based Nanoparticles, ACS Nano, 5(2011), 8488-8505. DOI: 10.1021/nn202378b

[17] S.Lazzari, et al., Colloidal stability of polymeric nanoparticles in biological fluids, $J$. Nanoparticle Res., 65(2012). DOI: 10.1007/s11051-012-0920-7

[18] M.Perween, D.B.Parmar, G.R.Bhadu, D.N.Srivastava, Polymer-graphite composite: A versatile use and throw plastic chip electrode, Analyst, 139(2014), no. 22, 5919-5926.

DOI: $10.1039 / \mathrm{c} 4 \mathrm{an} 01405 \mathrm{~g}$

[19] X.Wang, P.Wang, Y.Jiang, Q.Su, J.Zheng, Facile surface modification of silica nanoparticles with a combination of noncovalent and covalent methods for composites application, Compos. Sci. Technol, 104(2014), 1-8.

[20] J.H.Sung, H.S.Kim, H.J.Jin, H.J.Choi, I.J.Chin, Nanofibrous membranes prepared by multiwalled carbon nanotube/poly(methyl methacrylate) composites, Macromolecules, 37(2004), 9899-9902.

[21] L.Zhang, et al., Core-shell nanospheres to achieve ultralow friction polymer nanocomposites with superior mechanical properties, Nanoscale, 254(2019).

[22] W.-K.Kuo, H.-P.Weng, J.-J.Hsu, H.Yu, Photonic Crystal-Based Sensors for Detecting Alcohol Concentration, Appl. Sci., 6(2016), 67. DOI: 10.3390/app6030067

[23] S.Y.Lin, et al., A three-dimensional photonic crystal operating at infrared wavelengths, Nature, 394(1998), 251-253.

[24] A.Bearzotti, et al., Alcohol vapor sensory properties of nanostructured conjugated polymers, J. Phys. Condens. Matter, 65(2008). 
[25] K.Gipson, K.Stevens, P.Brown, J.Ballato, Infrared spectroscopic characterization of photoluminescent polymer nanocomposites, J. Spectrosc, 11(2015), 9. DOI: 10.1155/2015/489162

[26] I.Venditti, Gold nanoparticles in photonic crystals applications: A review, Materials (Basel), 10(2017), 97.

[27] H.-Q.Wang, M.Batentschuk, A.Osvet, L.Pinna, C.J.Brabec, Rare-Earth Ion Doped UpConversion Materials for Photovoltaic Applications, Adv. Mater., 23(2011), 2675-2680.

DOI: $10.1002 /$ adma.201100511

[28] B.Shao, et al., Coupling of Ag Nanoparticle with Inverse Opal Photonic Crystals as a Novel Strategy for Upconversion Emission Enhancement of NaYF 4?: Yb 3+, Er 3+ Nanoparticles, ACS Appl. Mater. Interfaces, 7(2015), 25211-25218.

[29] D.Bi, et al., Polymer-templated nucleation and crystal growth of perovskite films for solar cells with efficiency greater than 21\%, Nat. Energy, 9(2016).

[30] M.K.Assadi, et al., Enhancing the efficiency of luminescent solar concentrators (LSCs), Appl. Phys. A Mater. Sci. Process, 28(2016).

[31] L.Xu, et al., Increasing the Efficiency of Organic Dye-Sensitized Solar Cells over 10.3\% Using Locally Ordered Inverse Opal Nanostructures in the Photoelectrode, Adv. Funct. Mater., 28(2018), 1706291. DOI: 0.1002/adfm.201706291

[32] X.Huang, S.Han, W.Huang, X.Liu, Enhancing solar cell efficiency: the search for luminescent materials as spectral converters., Chem. Soc. Rev, 42(2013), 173-201.

[33] R.D'Amato, V I.enditti, M.V.Russo, M.Falconieri, Growth control and long-range selfassembly of poly(methyl methacrylate) nanospheres, J. Appl. Polym. Sci., 102(2006), 4493-4499.

[34] R.De Angelis, et al., From nanospheres to microribbons: Self-assembled Eosin Y doped PMMA nanoparticles as photonic crystals, J. Colloid Interface Sci. 414(2014), 24-32.

DOI: $10.1016 /$ j.jcis.2013.09.045

[35] I.V.Nemtsev, O.V.Shabanova, A.V.Shabanov, Electron microscopy investigation of polymethylmethacrylate spherical particles \& artificial opals based on it, Sib. J. Sci. Technol., 1(2012), 126-129.

[36] O.V.Shabanova, M.A.Korshunov, I.V.Nemtsev, A.V.Shabanov, Features of self-assembly of opal-like structures based on poly(methyl methacrylate) submicron dispersions, Nanotechnologies Russ., 11(2016), 633-639. DOI: 10.1134/S1995078016050153

[37] T.A.Taton, D.J.Norris, Defective promise in photonics, Nature, 416(2002), 685-686.

[38] T.Y.Kwon, J.Y.Ha, J.N.Chun, J.S.Son, K.H.Kim, Effects of prepolymerized particle size and polymerization kinetics on volumetric shrinkage of dental modeling resins, Biomed Res. Int., 14(2014), 6 . DOI: 10.1155/2014/914739

[39] O.V.Shabanova, A.V.Shabanov, I.V.Nemtsev, Research of conditions of synthesis of nanoscale monodisperse spherical particles of poly-methylmethacrylate, Siberian journal of science and technology, 4(2011), 201-205.

[40] A.Dukhin, S.Parlia, P.Somasundaran, Rheology of non-Newtonian liquid mixtures and the role of molecular chain length, J. Colloid Interface Sci., 560(2020), 492-501.

DOI: $10.1016 /$ j.jcis.2019.10.044 
[41] I.V.Nemtsev, I.A.Tambasov, A.A.Ivanenko, V.Y.Zyryanov, Angle-resolved reflection spectroscopy of high-quality PMMA opal crystal, Photonics Nanostructures - Fundam. Appl., 28(2018), 37-44. DOI: 10.1016/j.photonics.2017.11.007

[42] I.V.Nemtsev, O.V.Shabanova, N.P.Shestakov, A.V.Cherepakhin, Y.Y.Zyryanov, Morphology stability of polymethylmethacrylate nanospheres formed in water-acetone dispersion medium, Appl. Phys. A, 125(2019), 738-750.

\section{Синтез опалов из частиц полиметилметакрилата в дисперсионных средах с различной вязкостью}

Иван В. Немцев

Федеральный исследовательский центр КНЦ СО РАН Красноярск, Российская Федерация Институт физики им. Л.В.Киренского

Красноярск, Российская Федерация

Сибирский федеральный университет Красноярск, Российская Федерация

Ольга В. Шабанова Специальное Конструкторско-Технологическое Бюро «Наука» Красноярск, Российская Федерация

\footnotetext{
Аннотация. Фотонные кристаллы - это структуры, которые имеют пространственную архитектуру с периодически изменяющейся сложной диэлектрической функцией в масштабах, сопоставимых с длинами волн света в видимом диапазоне частот. Целью данной работы является получение трёхмерных фотонных кристаллов путём самосборки из субмикронных сферических монодисперсных частиц полиметилметакрилата в дисперсных средах с различной вязкостью.

Ключевые слова: безэмульсионная полимеризация, вязкость дисперсионной среды, гранулы ПММА, субмикросфера, самосборка, 2D и 3D коллоидные кристаллы, фотонный кристалл, метаматериал, СЭМ-микрофотографии, ИК-спектроскопия.
} 